\title{
On the cause of the tailing phenomenon during virus disinfection by chlorine dioxide
}

\section{Thérèse Sigstam, Andreas Rohatschek, Qingxia Zhong, Moritz Brennecke, Tamar Kohn*}

Laboratory of Environmental Chemistry, School of Architecture, Civil and Environmental Engineering (ENAC), École Polytechnique Fédérale de Lausanne (EPFL), CH-1015 Lausanne, Switzerland

\section{A R T I C L E I N F O}

Article history:

Received 3 June 2013

Received in revised form

5 September 2013

Accepted 7 September 2013

Available online 19 September 2013

Keywords:

Chlorine dioxide

Viruses

Tailing

Reversible protection

MALDI

Resistant subpopulation

\begin{abstract}
A B S T R A C T
This study investigates the mechanisms underlying the deviation from Chick-Watson kinetics, namely a tailing curve, during the disinfection of viruses by chlorine dioxide $\left(\mathrm{ClO}_{2}\right)$. Tailing has been previously reported, but is typically attributed to the decay in disinfectant concentration. Herein, it is shown that tailing occurs even at constant $\mathrm{ClO}_{2}$ concentrations. Four working hypothesis to explain the cause of tailing were tested, specifically changes in the solution's disinfecting capacity, aggregation of viruses, resistant virus subpopulations, and changes in the virus properties during disinfection. In experiments using MS2 as a model virus, it was possible to rule out the solution's disinfecting capacity, virus aggregation and the resistant subpopulation as reasons for tailing. Instead, the cause for tailing is the deposition of an adduct onto the virus capsid over the course of the experiment, which protects the viruses. This adduct could easily be removed by washing, which restored the susceptibility of the viruses to $\mathrm{ClO}_{2}$. This finding highlights an important shortcoming of $\mathrm{ClO}_{2}$, namely its self-limiting effect on virus disinfection. It is important to take this effect into account in treatment applications to ensure that the water is sufficiently disinfected before human consumption.
\end{abstract}

(c) 2013 Elsevier Ltd. All rights reserved.

\section{Introduction}

Chlorination is among the oldest and most commonly used disinfection process worldwide. However, over the years it has been shown that chlorine produces harmful by-products such as trihalomethanes and other halogenated compounds with potential carcinogenic effects (Xie, 2004). It is therefore of interest to investigate other disinfectants that have a similar disinfection potential but generate fewer problematic byproducts. As a good alternative, chlorine dioxide $\left(\mathrm{ClO}_{2}\right)$ has shown to efficiently disinfect water for human consumption (Huang et al., 1997; Jin et al., 2013; Zoni et al., 2007).
Importantly, it is effective at inactivating Cryptosporidium, whereas free chlorine is not (Chauret et al., 2001). Except from exhibiting a good disinfection capacity, $\mathrm{ClO}_{2}$ can also oxidize iron and manganese, as well as help controlling taste and odor compounds (Aieta and Berg, 1986; Li et al., 1996). The disadvantage of using chlorine dioxide is that it reacts to chlorite, which may be neurotoxic at high doses (Xie, 2004).

In 1908, Chick published the first model for describing bacteria inactivation by disinfecting agents (Chick, 1908). The model suggests that the fraction of surviving organisms $\left(C_{\mathrm{v}}\right)$ $\mathrm{C}_{\mathrm{v}, \mathrm{o}}$ ) exponentially decreases with time, which then leads to a linear decrease of $\ln \left(C_{\mathrm{v}} / C_{\mathrm{v}, 0}\right)$ with time:

\footnotetext{
* Corresponding author. Tel.: +41216930891.

E-mail address: tamar.kohn@epfl.ch (T. Kohn).
} 
$\ln \left(C_{\mathrm{v}} / C_{\mathrm{v}, 0}\right)=-k \mathrm{t}$

Here, $k$ represents the inactivation rate constant, $C_{v}$ is the concentration of infective virus and the time of disinfection. In order to be able to compare different disinfectant concentration, this model was expanded by Watson (1908) to yield the well-known Chick-Watson model:

$\ln \left(C_{\mathrm{v}} / C_{\mathrm{v}, 0}\right)=-k_{\mathrm{cw}} C^{n} \mathrm{t}$

where $k_{\mathrm{cw}}$ is the Chick-Watson inactivation rate constant, $C$ is the disinfectant concentration, and $n$ is an empirical constant also called the dilution coefficient. Frequently it is found that $n=1$, in which case the Chick-Watson model is first-order with respect to the disinfectant dose (expressed as Ct). This model thus allows calculating the disinfectant dose necessary to obtain a certain amount of inactivation. It was quickly discovered, however, that inactivation kinetics occasionally deviate from this simple model. In particular, inactivation curves frequently exhibit tailing after an initial exponential decay. The reason for this observed deviation divided the researchers into two main groups: the vitalistics, who argued that this deviation originated from heterogeneity in the population of microorganisms, and the mechanistics, who attributed these deviations to factors occurring during the disinfection process (Hiatt, 1964). To date, the mechanism underlying this deviation from Chick-Watson's first-order model still hasn't been fully assessed and understood (Harakeh and Butler, 1984). Cerf stated in his review on tailing of survival curves (Cerf, 1977) that: "People who have observed tails or who have considered the question, either accept tails as facts or reject them as artefacts". In other words, even though tailing is frequently observed, little attention has been given to its underlying cause. The occurrence of tailing, however, may lead to incomplete inactivation and ultimately may cause the disinfection process to fall short of the treatment goal. It is thus important to account for tailing, in order to ensure that water or food is sufficiently disinfected prior to human consumption.

Tailing appears to be particularly common in the case of virus disinfection by $\mathrm{ClO}_{2}$. Examples include the inactivation of adenovirus, feline calicivirus, enterovirus 71, murine norovirus and human and simian rotavirus (Berman and Hoff, 1984; Chen and Vaughn, 1990; Jin et al., 2013; Lim et al., 2010; Thurston-Enriquez et al., 2005). Yet its occurrence was either not mentioned or simply attributed to the decay in chlorine dioxide concentration over time of reaction. In a recent study, Hornstra et al. (2010) performed an in-depth investigation on the disinfection of bacteriophage MS2 at low $\mathrm{ClO}_{2}$ concentrations, and suggested that heterogeneity of the virus population (either in the original virus stock or acquired during disinfection) could be the reason for the tailing behavior. This hypothesis, however, was not proven, nor were other possible causes for the tailing behavior investigated in depth.

In the present work, we test the resistant subpopulation hypothesis, along with three other possible mechanisms that can lead to tailing: the presence of viral aggregates; changes in the solution properties during disinfection that diminish the efficiency of $\mathrm{ClO}_{2}$; and changes in the virus properties during disinfection that protect them from $\mathrm{ClO}_{2}$.

\section{Materials and methods}

Virus disinfection experiments were conducted in stirred dilution buffer (DB: $5 \mathrm{mM} \mathrm{PO}_{4}^{2-}, 10 \mathrm{mM} \mathrm{NaCl}, \mathrm{pH}$ 7.4). MS2 was used as the test organism, because it is a commonly used surrogate for human viruses (Grabow, 2001) and to facilitate the comparison of our results with the study by Hornstra et al. (2010). At several time points during the inactivating treatment, samples were analyzed for the remaining virus infectivity. Experiments were typically conducted in two or more replicates with good reproducibility. Exceptions are the tests involving pretreatments with sonication, chloroform and filtration (see Section 3.2), which were conducted only once.

\subsection{Chemicals}

$\mathrm{NaCl}$ (99.5\%), $\mathrm{NaOH}$ (extrapure), $\mathrm{NaH}_{2} \mathrm{PO}_{4} \cdot \mathrm{H}_{2} \mathrm{O}$ (99\%), $\mathrm{K}_{2} \mathrm{~S}_{2} \mathrm{O}_{8}$ (99\%), $\mathrm{NaHCO}_{3}(99.7 \%)$ and $\mathrm{CHCl}_{3}(99.8 \%)$ were purchased from Acros Organics (Geel, Belgium). $\mathrm{Na}_{2} \mathrm{~S}_{2} \mathrm{O}_{3}$ (98\%), sinapinic acid (98\%) and $\mathrm{NaClO}_{2}$ (puriss.) was obtained from Sigma-Aldrich (Germany). $\mathrm{HCl}$ (25\%) was obtained from Merck (Darmstadt,

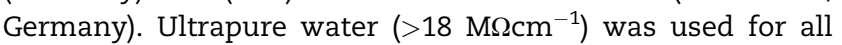
aqueous solutions.

\subsection{Microorganisms}

Bacteriophage MS2 (DSMZ 13767) and its Escherichia coli host (DSMZ 5695) were purchased from the German Collection of Microorganisms and Cell Cultures (Braunschweig, Germany). It was propagated as described previously (Pecson et al., 2009) and infectivity was assessed by enumeration of plaque forming units (pfu) using the double agar layer method (Walter, 1961).

\subsection{Chlorine dioxide production and experimental setup}

Chlorine dioxide was produced by mixing $100 \mathrm{~mL} 4 \% \mathrm{~K}_{2} \mathrm{~S}_{2} \mathrm{O}_{8}$

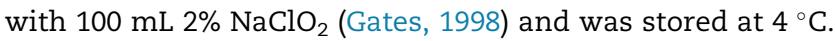
The resulting $\mathrm{ClO}_{2}$ stock concentration $(250-1000 \mathrm{mg} / \mathrm{L})$ was determined by spectrophotometry $\left(\varepsilon_{358 \mathrm{~nm}}=1200 \mathrm{M}^{-1} \mathrm{~cm}^{-1}\right)$ (Hoigne and Bader, 1994). Prior to experiments, the stock solution was diluted to a working solution of $0.4-0.7 \mathrm{mg} / \mathrm{L}$ $\mathrm{ClO}_{2}$, and was spiked with virus stock solution to a concentration of $0.5-1 \times 10^{12} \mathrm{pfu} / \mathrm{mL}$. To compensate for $\mathrm{ClO}_{2}$ evaporation and consumption throughout the experiment, concentrated $\mathrm{ClO}_{2}(16 \mathrm{mg} / \mathrm{L})$ was added at a rate of $8-20 \mu \mathrm{L} /$ min by means of a peristaltic pump (KdScientific). Prior to the start of each experiment it was ensured that this setup maintained a constant $\mathrm{ClO}_{2}$ concentration under the given solution conditions. To halt the disinfection, $\mathrm{ClO}_{2}$ was quenched by addition of sodium thiosulfate (0.63 M) at a 20:1 sample:quenching agent ratio. Control samples confirmed that the addition of sodium thiosulfate did not result in inactivation.

\subsection{Re-growth of MS2 after inactivation}

After disinfection, the solution was centrifuged using a $100 \mathrm{kDa}$ Microcon centrifugal filter (Millipore, Billerica, MA) 
and concentrated to $20 \mu \mathrm{L}$. The centrifuged sample was washed 5 times with $\mathrm{DB}$, and $50 \mu \mathrm{L}$ of $\mathrm{DB}$ was added. Of this solution, $50 \mu \mathrm{L}$ were spiked into a $12 \mathrm{~mL}$ E. coli culture in exponential growth phase at an optical density of 0.04 . After $5 \mathrm{~h}$ of incubation at $37^{\circ} \mathrm{C}, 1 \mathrm{~mL}$ of $\mathrm{CHCl}_{3}$ was added to lyse the bacteria. The solution was then centrifuged at $3000 \mathrm{~g}$ for $5 \mathrm{~min}$ to pellet the bacteria. The supernatant was concentrated to $1 \mathrm{~mL}$ in a $100 \mathrm{kDa}$ Microcon centrifugal filter and was washed 4 times with DB. Finally the virus solution was passed through a $0.1 \mu \mathrm{m}$ filter and was used for the next inactivation-growth cycle. This procedure was repeated after each disinfection experiment for 5 cycles.

\subsection{Particle size measurement by dynamic light scattering (DLS)}

Hydrodynamic size measurements were performed by Zetasizer (Malvern Instruments, Nano ZS) in disposable $120 \mu \mathrm{L}$ cuvettes. The cuvettes were always placed in the instrument with the same orientation and care was taken to avoid air bubbles. The data acquisition software (Dispersion Technology Software 5.10, Malvern Instruments Ltd.) was set to 13 runs of $10 \mathrm{~s}$ in each measurement. Each measurement was repeated at least three times.

\subsection{Analysis of the capsid protein by matrix assisted laser desorption ionization (MALDI)}

To assess the effect of $\mathrm{ClO}_{2}$ on the capsid proteins, $10 \mathrm{~mL}$ of $1.5 \mathrm{mg} / \mathrm{L}$ chlorine dioxide were spiked with virus to a final MS2 concentration of $1 \times 10^{12} \mathrm{pfu} / \mathrm{mL}$. Because thiosulfate can back-reduce oxidized protein residues, disinfection experiments in which protein integrity was assessed were conducted by the one-time addition of $\mathrm{ClO}_{2}$, which was then left to evaporate as was described before (Sigstam et al., 2013). All MALDI measurements were performed with an ABI 4800 MALDI-TOF-TOF (Applied Biosystems, Rotkreuz, Switzerland), using the instrument settings and sample deposition methods described previously (Wigginton et al., 2010).

\subsection{Analysis of disinfection kinetics}

As described in previous work (Sigstam et al., 2013), chlorine dioxide inactivation kinetics of MS2 deviate from the firstorder Chick-Watson model and can be described by the Hom model according to the following equation (Haas and Joffe, 1994):

$\ln \left(C_{\mathrm{v}} / C_{\mathrm{v}, 0}\right)=-k_{\mathrm{H}} C^{n} t^{m-1}$

where $C$ is the disinfectant concentration (constant over the time of reaction), $k_{\mathrm{H}}$ is the Hom rate constant $\left[\left(\mathrm{mg} \mathrm{L}^{-1} \mathrm{~s}^{m-1}\right)^{-1}\right]$, $n$ is the dilution coefficient (set to 1 as only a single $\mathrm{ClO}_{2}$ concentration was used), and $m$ is an empirical constant that describes the deviation from the ideal Chick-Watson model. The parameters for the Hom model were fitted in Sigmaplot (version: 12.0, 2011). Model fits were compared by ANCOVA analysis as described previously (Sigstam et al., 2013). The correlation coefficient $(R)$ for all fits varied between 0.97 and 0.99 .

\section{Results and discussion}

Fig. 1 shows an example inactivation curve obtained for MS2 after exposure to a constant concentration of $0.5 \mathrm{mg} / \mathrm{L}$ chlorine dioxide. It is readily seen that after 4 logs inactivation a tail starts to form. The most obvious reason for a tailing disinfection curve is the consumption of the disinfectant over time, as has been suggested in other studies (Lim et al., 2010; Xue et al., 2013). As can be seen in Fig. 1, however, we demonstrate that $\mathrm{ClO}_{2}$ consumption is not the sole reason for tailing, as this feature is evident even though the chlorine dioxide concentration in our experiments was maintained constant.

Interestingly, no tailing effect was observed for the inactivation of MS2 by other oxidants, such as free chlorine, peracetic acid or singlet oxygen (Mattle et al., 2011; Sigstam et al., 2013; Wigginton et al., 2012). The tailing feature must therefore be related to the specific mode of action of $\mathrm{ClO}_{2}$. An important feature in $\mathrm{ClO}_{2}$ 's mode of action is that, unlike other oxidants studied, it does not act on the MS2 genome, but solely on its proteins (Sigstam et al., 2013; Wigginton et al., 2012). Recombination of damaged genomes, which has been suggested as the cause for tailing during $\mathrm{UV}_{254}$ disinfection (Mattle and Kohn, 2012), can therefore be ruled out for $\mathrm{ClO}_{2}$. The tailing observed in $\mathrm{ClO}_{2}$ disinfection must instead stem from an increasingly inhibited reactivity or accessibility of $\mathrm{ClO}_{2}$ toward MS2 proteins.

Starting from this insight, the present study intended to determine the feature specific to $\mathrm{ClO}_{2}$ disinfection that results in tailing. To do so, four main factors can be hypothesized as the underlying cause:

1. Changes in solution properties: The disinfecting capacity of the chlorine dioxide solution changes over time of reaction.

2. Aggregation: In the virus stock, a fraction of viruses are in an aggregated state which may protect them from inactivation. Aggregation could also occur during disinfection.

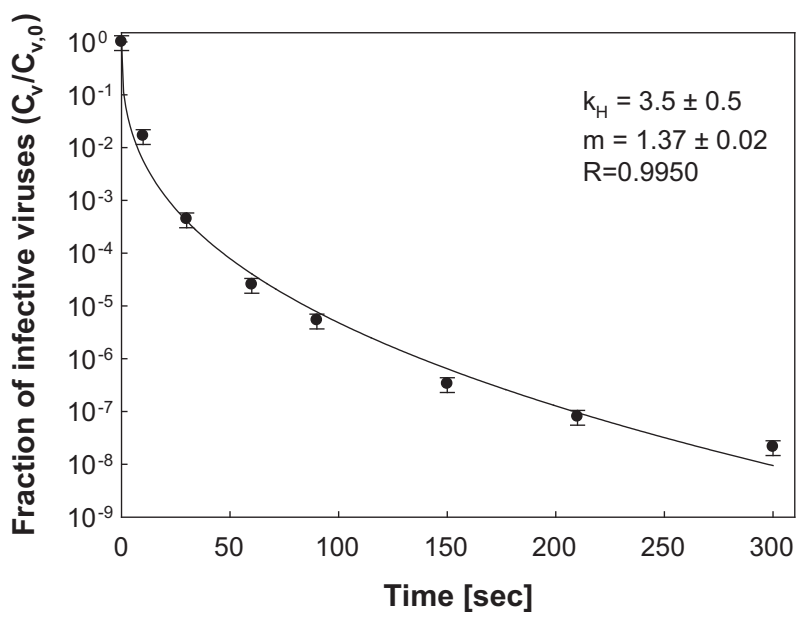

Fig. 1 - Inactivation of MS2 by chlorine dioxide. $\mathrm{ClO}_{2}$ concentration was $0.6 \mathrm{mg} / \mathrm{L}$. The line indicates the fit to the Hom model (Eq. (3)). The error bars represent the standard deviation associated with virus enumeration. 
3. Resistant subpopulation: The initial virus stock contains different subpopulations with variable resistance to chlorine dioxide.

4. Changes in virus properties: The disinfection process changes virus properties such that they are increasingly protected against the disinfectant.

Of these four causes, the first three were suggested by Hornstra et al. (2010) and are investigated in detail here. The fourth cause, however, has not previously been considered. In the following, we discuss our experimental results leading to the inclusion or rejection of each of these four hypotheses.

\subsection{Changes in solution properties}

To assess if changes in solution properties over the course of a disinfection experiment are the cause of tailing, three factors were examined: the influence of the buffer, the role of the accumulating disinfection by-product chlorite, and the disinfection efficiency of spent solution.

The influence of the buffer was tested to ensure that the observed disinfection behavior was not an artifact arising from interactions of $\mathrm{ClO}_{2}$ with the matrix. Specifically, we exchanged DB for carbonate buffer (5 mM). In Fig. 2, a comparison of the inactivation rate constants determined in carbonate buffer and in $\mathrm{DB}$ is shown. The corresponding inactivation curves and Hom model fits are shown in the Supplementary material (Fig. S1). It can be seen that this buffer exchange didn't affect the observed inactivation kinetics, indicating that the phosphate is not essential to the tailing process.

The disinfection by-product chlorite is formed during the reaction between chlorine dioxide and amino acids

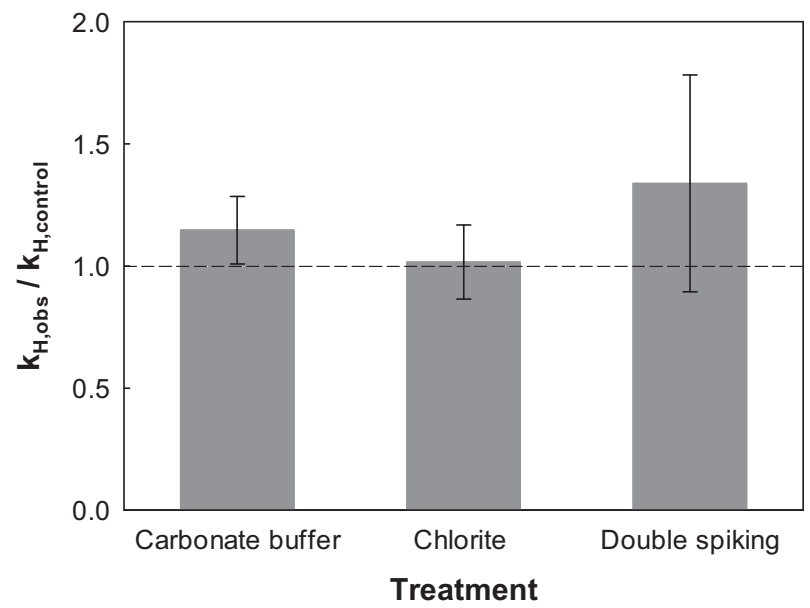

Fig. 2 - Impact on $k_{\mathrm{H}}$ due to changes in solution properties. Ratio of $k_{\mathrm{H}}$ obtained in a control experiment $\left(0.5 \mathrm{mg} / \mathrm{L} \mathrm{ClO}{ }_{2}\right)$ and in experiments with changed solution conditions: left: experiment conducted in carbonate buffer instead of DB; middle: experimental solution containing chlorite $(6.0 \mathrm{mg} /$ L); right: solution re-spiked with fresh MS2 after $120 \mathrm{~s}$ of reaction. The dashed line represents equal $k_{H}$ in the sample and the control. The error bars represent the propagated standard error associated with the model fits of $k_{\mathrm{H}}$.
(Napolitano et al., 2005), thereby changing the composition of the matrix during the experiment. If chlorite interfered with the disinfection efficiency of $\mathrm{ClO}_{2}$, its accumulation in solution over time may explain the tailing effect. Figs. 2 and S2 show a comparison of the inactivation rate constants and curves determined from an experiment with chlorite added to the solution at the beginning of the disinfection process and the control experiment (without added chlorite). The amount of chlorite added corresponded to the amount chlorite produced over the time of a control experiment (3-6 mg/L). As can be seen in Fig. 2, addition of chlorite did not cause a significant change in $k_{\mathrm{H}}(p=0.98)$. Similarly, $\mathrm{m}$ did not change significantly $(p=0.42)$. The lack of change in $k_{\mathrm{H}}$ and $m$ values in the presence of chlorite implies that the tailing effect was present, and that its onset occurred at the same extent of inactivation as in the control experiment. The gradual accumulation of chlorite during disinfection can therefore not explain tailing.

The most conclusive experiment in this series consisted of spiking fresh virus into a spent solution. This experiment was performed to confirm the findings by Hornstra et al. (2010). Specifically, MS2 disinfection was monitored for $120 \mathrm{~s}$, well into the tailing zone (Fig. 1). Then the solution was re-spiked with fresh viruses, and disinfection was monitored for an additional $120 \mathrm{~s}$. The second virus spike showed the same kinetic parameters as the first spike (Figs. 2 and S3), indicating that exposing fresh viruses to a spent solution didn't change the disinfection kinetics. This is in agreement with the result of a similar experiment obtained by Hornstra et al. (2010). Combined, the results from these experiments conclusively confirm that changes in solution properties are not responsible for the observed tailing effect.

\subsection{Aggregation}

A previous study has shown that strong disinfectants are readily consumed at the outermost layer of virus aggregates, and therefore only a reduced disinfectant concentration reaches the aggregate core (Mattle et al., 2011). The innermost viruses thus become inactivated at a slower rate. Furthermore, if viruses are enumerated in an aggregated state, it is not possible to distinguish if only one or several viruses in the aggregate remain infective. The number of surviving viruses therefore appears constant, even if disinfection within the aggregate continues. Both these factors lead to a tailing feature in the disinfection curve of partially or fully aggregated samples, as has been reported in various studies (Sharp et al., 1975; Thurston-Enriquez et al., 2003).

MS2 has an isoelectric point of 3.9, which implies that at the working $\mathrm{pH}$ of this study (7.4), most viruses should be dispersed. However, it is possible that the solution contains aggregates that were formed in the host cell during the virus propagation process. In Fig. 3, the size distribution of the virus solution is shown; the first peak at about $30 \mathrm{~nm}$ represents single MS2 particles, (MS2 diameter $=26 \mathrm{~nm}$ ). In addition, a larger particle population can be seen, which could be virus aggregates or impurities arising from the virus propagation or sample handling. Note that Fig. 3 shows the signal intensity, which is proportional to $r^{6}$, where $r$ is the particle radius. Even though the intensity peaks in Fig. 3 for the small and large 


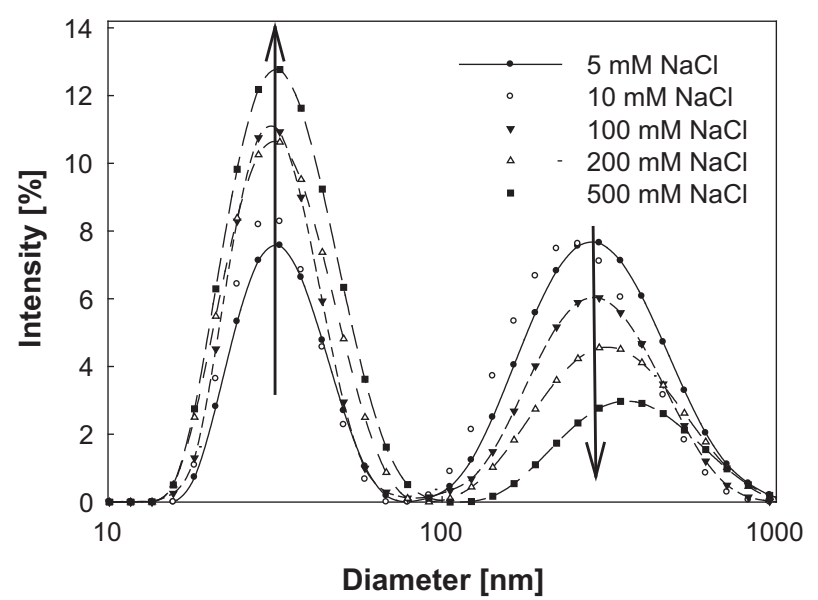

Fig. 3 - Size distribution of MS2 at different ionic strengths. The MS2 concentration was $5 \times 10^{11} \mathrm{pfu} / \mathrm{mL}$. Each data point represents the average of three DLS measurements.

particles have similar areas, the number of larger particles is thus very small compared to the single viruses.

To determine if the tailing phenomenon arises from the presence of few small aggregates seen in Fig. 3, we attempted to break up any aggregates in solution. To do so, the virus solution was subjected to different treatments prior to disinfection. Firstly, the sample was sonicated during $30 \mathrm{~min}$. This treatment has previously been shown to be efficient in dispersing aggregated viruses (Hejkal et al., 1981). Secondly, the virus stock was subjected to chloroform extraction. Chloroform extraction is used during virus production to purify and disperse viruses after propagation (ThurstonEnriquez et al., 2003). Therefore it was assumed that treating the stock solution with chloroform before disinfection may break up residual aggregates. Thirdly, the virus stock was filtered through a $0.1 \mu \mathrm{m}$ pore size filter. This ensured that no particles larger than $0.1 \mu \mathrm{m}$ in diameter stayed in solution. But given that the diameter of one virus is $26 \mathrm{~nm}$, an aggregate of $100 \mathrm{~nm}$ in diameter could still be composed of $10-20$ viruses, which may have a protective effect on the viruses located in the core of the aggregate. Finally, the ionic strength of the buffer solution was increased, as previous studies have suggested that high ionic strength disperses viral aggregates (Floyd and Sharp, 1977). As shown in Fig. 3, this effect was also evident in our experimental system. The intensity of the single virus peak increased slightly and the intensity of larger particles decreased with higher salt concentrations. This indicates a shift from aggregates to single particles. This finding may be surprising, as it is contrary to the double layer theory, which suggests that the interaction between equally charged particles should increase with increasing $\mathrm{NaCl}$ concentration, due to increasing charge shielding (Delgado et al., 2005). However, a similar finding was reported previously for polio and reovirus by Floyd and Sharp (1978), who suggested that dispersion could be due to cations binding to the virus, which results in positively charged particles with repulsive forces.

Fig. 4 shows a comparison of the inactivation rate constants determined from experiments with broken up aggregates compared to a control experiment (without any pre-treatment on the virus or the solution). The corresponding inactivation curves and model fits are shown in the Supplementary material (Figs. S4-S7). While none of the treatments described above eliminated tailing, filtration and increasing ionic strength slightly increased the inactivation rate constant $(p=0.05$ for filtration and $p<0.01$ for the high ionic strength solution). An increase in $k_{\mathrm{H}}$ represents more rapid inactivation before as well as after the onset of tailing. This behavior can be interpreted as the removal or break up of some, but not all aggregates. The biggest increase in $k_{\mathrm{H}}$ was found for the solution with high ionic strength (Fig. S7). However, even in this solution a tailing still appeared. In fact, no significant differences were found among these experiments and the control for the second model parameter, $m$ (data not shown). This indicates that all experiments deviated similarly from first-order Chick-Watson kinetics, and that the dispersal or removal of aggregates in the virus stock solution could not explain the tailing effect. In addition, aggregation would also affect the inactivation curves of other disinfectants. However, as mentioned above, no tailing effect was observed for free chlorine or singlet oxygen (Sigstam et al., 2013). This further indicates that aggregates in the viral stocks do not contribute to the tailing exhibited during chlorine dioxide disinfection.

An aggregation effect on inactivation could also occur if aggregates form during, rather than prior to, the disinfection process. While the size measurements by DLS didn't indicate any change in the particle size during disinfection, small aggregates may have formed at concentrations below the detection limit of the DLS. To assess if any aggregation occurred during the experiment, the disinfection was stopped

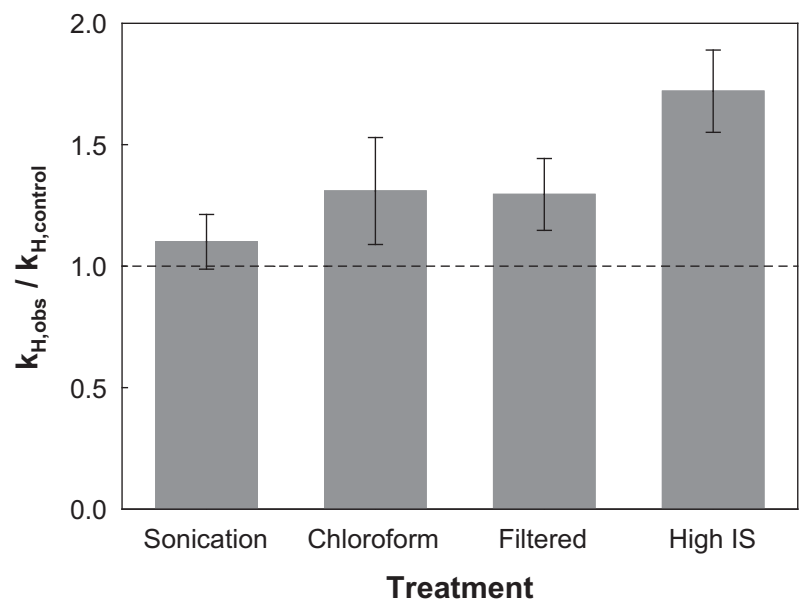

Fig. 4 - Impact of aggregate dispersion on $k_{\mathrm{H}}$. Ratio of $k_{\mathrm{H}}$ obtained in pre-treated virus samples and control experiments. Sonication $=$ sample sonicated for $30 \mathrm{~min}$; Chloroform = sample extracted using chloroform; Filtered = sample passed through a filter of $0.1 \mu \mathrm{m}$ pore size; High IS = sample exposed to a solution of high ionic strength containing $500 \mathrm{mM} \mathrm{NaCl}$. The dashed line indicates equal $k_{\mathrm{H}}$ in the sample and the control. The error bars represent the propagated standard error associated with the model fits of $k_{\mathrm{H}}$. 
(by discontinuing the addition of $\mathrm{ClO}_{2}$ ) after $120 \mathrm{~s}$, and the sample was subjected to $10 \mathrm{~min}$ of sonication to break any newly formed aggregates before re-starting the disinfection. The disinfection kinetics in this experiment showed no difference to the non-sonicated control experiment, neither in $k_{\mathrm{H}}$ $(p=0.09)$ nor in $m(p=0.39)$. This indicates either that no aggregates formed during the short time of reaction or that the aggregates formed are not dispersible.

For more conclusive evidence that aggregation during disinfection did not play a role, the MS2 starting concentration was lowered. Fewer viruses in solution lead to fewer chances of virus encounter, and hence to less aggregation. Experiments were therefore performed at starting concentrations of $1 \times 10^{7} \mathrm{pfu} / \mathrm{mL}$ and $5 \times 10^{9} \mathrm{pfu} / \mathrm{mL}$. The inactivation behavior was not significantly different from that of the control experiments with $5 \times 10^{11} \mathrm{pfu} / \mathrm{mL}$ as the starting MS2 concentration $(p=0.16)$. Furthermore, the onset of tailing occurred after the same extent of inactivation for all starting concentrations, confirming that aggregation during disinfection was not the cause for tailing.

\subsection{Resistant subpopulation}

So far we established that neither changes in solution properties, nor aggregation could explain the tailing feature. As proposed by Hornstra et al. (2010), tailing could arise from the presence of a resistant subpopulation in the starting virus stock. To support this theory they re-spiked the viruses from the tail directly into fresh chlorine dioxide solution and found that the inactivation continued in the slow, tailing phase. This finding is consistent with the presence of a resistant subpopulation, but doesn't exclude the possibility of a change in the virus properties. We therefore conducted two additional experiments to determine if a resistant subpopulation was present in the virus stock.

First, the potentially resistant virus population, i.e., the virus population surviving throughout the tailing phase of the experiment, was isolated and re-grown, and the re-grown viruses were re-exposed to $\mathrm{ClO}_{2}$. After five such disinfection and re-growth cycles, no change in virus disinfection kinetics was observed. In other words, repeated re-growth of the surviving population and re-exposure to $\mathrm{ClO}_{2}$ did not yield a more resistant MS2 population. This indicates that either no resistant subpopulation was present, or that the remaining wild types dominated the re-growth phase.

Second, the chlorine dioxide concentration in solution was increased five-fold after $120 \mathrm{~s}$ to attempt to disinfect the potentially resistant subpopulation with a higher $\mathrm{ClO}_{2}$ dose (Fig. S8). This measure did not cause any change in the inactivation behavior of the virus. In other words, the tailing part of the curve exhibited the same slow inactivation as seen in Fig. $1(p=0.20)$. This indicates that, if a resistant subpopulation is present, it exhibits slow inactivation kinetics that are in conflict with Chick-Watson kinetics, as they are independent of the $\mathrm{ClO}_{2}$ concentration. While this finding does not conclusively rule out the hypothesis of a resistant subpopulation, it appears unlikely that a subpopulation exists that has $\mathrm{ClO}_{2}$-independent disinfection kinetics. Instead, this result appears to be more consistent with our final hypothesis, namely a change in virus properties during disinfection.

\subsection{Changes in virus properties}

In order to evaluate if changes in the virus properties caused the virus to become more protected toward $\mathrm{ClO}_{2}$ over the course of the experiment, the virus solution was first subjected to inactivation into the tailing region. It was then washed in $100 \mathrm{kDa}$ Microcon centrifugal filters (Millipore, Billerica, MA) with DB, and subsequently re-exposed to chlorine dioxide. The important difference of this experiment compared to that by Hornstra et al. (2010) discussed above is the washing step prior to re-exposure to $\mathrm{ClO}_{2}$. As shown in Fig. 5, the washed sample exhibited fully restored reactivity toward chlorine dioxide, manifested by an initial exponential decay, followed by tailing after 3-4 logs of inactivation. In contrast, as reported by Hornstra et al., unwashed samples from the tailing region remained protected toward $\mathrm{ClO}_{2}$. This observation indicates that the viruses acquire protection during the disinfection process, but that the protection is easily reversible by washing with $\mathrm{DB}$. This recovery of biphasic disinfection kinetics weakens the argument of a resistant subpopulation.

To better understand the effect of the washing step, the samples were subjected to MALDI mass spectrometry before and after washing, to determine if there was any change in the mass of the viral capsid protein. MS2's capsid protein is composed of 180 copies of one single protein of 129 amino acids, which is readily detectable by protein mass spectrometry. Results from the MALDI analyses are illustrated in Fig. 6. Untreated control samples show a strong peak at a mass to charge ratio $(\mathrm{m} / \mathrm{z})$ of $13.7 \mathrm{kDa}$, consistent with the mass of the MS2 capsid protein. After treatment with $\mathrm{ClO}_{2}$, the capsid protein peak shifted and appeared as a broad peak consisting of several masses. When the sample was washed after treatment, however, the intact capsid protein peak re-emerged.

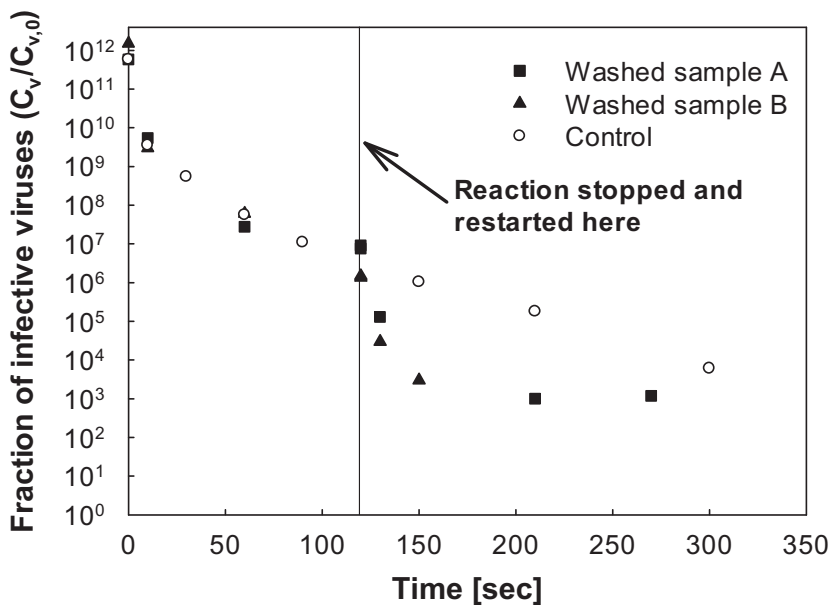

Fig. 5 - Effect of washing on the inactivation of MS2 by chlorine dioxide. At time $=0$, the solution was spiked to a MS2 concentration of $1 \times 10^{12} \mathrm{pfu} / \mathrm{mL}$. The reaction was stopped after $120 \mathrm{~s}$ (solid line), and the viruses were washed with $\mathrm{DB}$ and re-exposed to chlorine dioxide. The starting concentration after washing was $5 \times 10^{6} \mathrm{pfu} / \mathrm{mL}$ ). Triangles and squares indicate duplicate experiments, and a control sample (not washed; empty circles) is shown for comparison. 
These mass spectrometry results showed that indeed a protected population of viruses is created during the disinfection process by deposition of disinfection products onto the viral capsid proteins. However, the viruses can shed their protective layer relatively easily by washing. The masses observed in the unwashed mass spectra (Fig. 6) cannot be readily assigned to a specific reaction product. The +67 peak may result from adsorbed chlorite formed from the reaction between chlorine dioxide and an amino acid, but more work is needed to conclusively assign the individual peaks to specific capsid protein adducts, and to determine their effect with respect to protection from $\mathrm{ClO}_{2}$.

Previous work in our group (Sigstam et al., 2013) showed that damage to the capsid protein incurred during chlorine dioxide exposure is directly proportional to inactivation, suggesting that capsid protein damage may be involved in the inactivation of the virus. In the present study it is shown that disinfection products bind to the protein and protect the virus from further inactivation. This corroborates that the capsid protein is an important feature controlling the inactivation of MS2 by chlorine dioxide.

\section{Conclusions}

This study shows that the main cause for tailing during the disinfection of MS2 by chlorine dioxide is a change in the virus properties during the course of the experiment. Specifically, the reaction of $\mathrm{ClO}_{2}$ with $\mathrm{MS} 2$ creates products that deposit onto the viruses and protect them from further disinfection. This protection takes place on the capsid protein, which gets extensively but reversibly modified during the disinfection process. Other proposed causes for tailing, namely changes to the reactivity of the disinfecting solution, virus aggregation, and the presence of resistant subpopulations, could be ruled out.

Virus disinfection by $\mathrm{ClO}_{2}$ is thus a self-limiting process, in that it increasingly inhibits its own inactivation efficiency as the disinfection treatment proceeds. This is an important and potentially detrimental characteristic of this disinfectant, which should be recognized by water utilities working with $\mathrm{ClO}_{2}$. Specifically, the self-limiting effect may cause the disinfection of viruses to fall short of the required treatment goal. Further work is needed, however, to determine if the protective effect is observed to the same extent for other $\mathrm{ClO}_{2}$ doses. Similarly, in the application of $\mathrm{ClO}_{2}$ for virus disinfection in actual drinking water matrices should be tested to establish if protecting adducts preferably bind to organic matter rather than the virus, which may reduce the tailing effect. Finally, more work is required using a selection of different viruses, to establish if this effect is equally important across virus species and families.
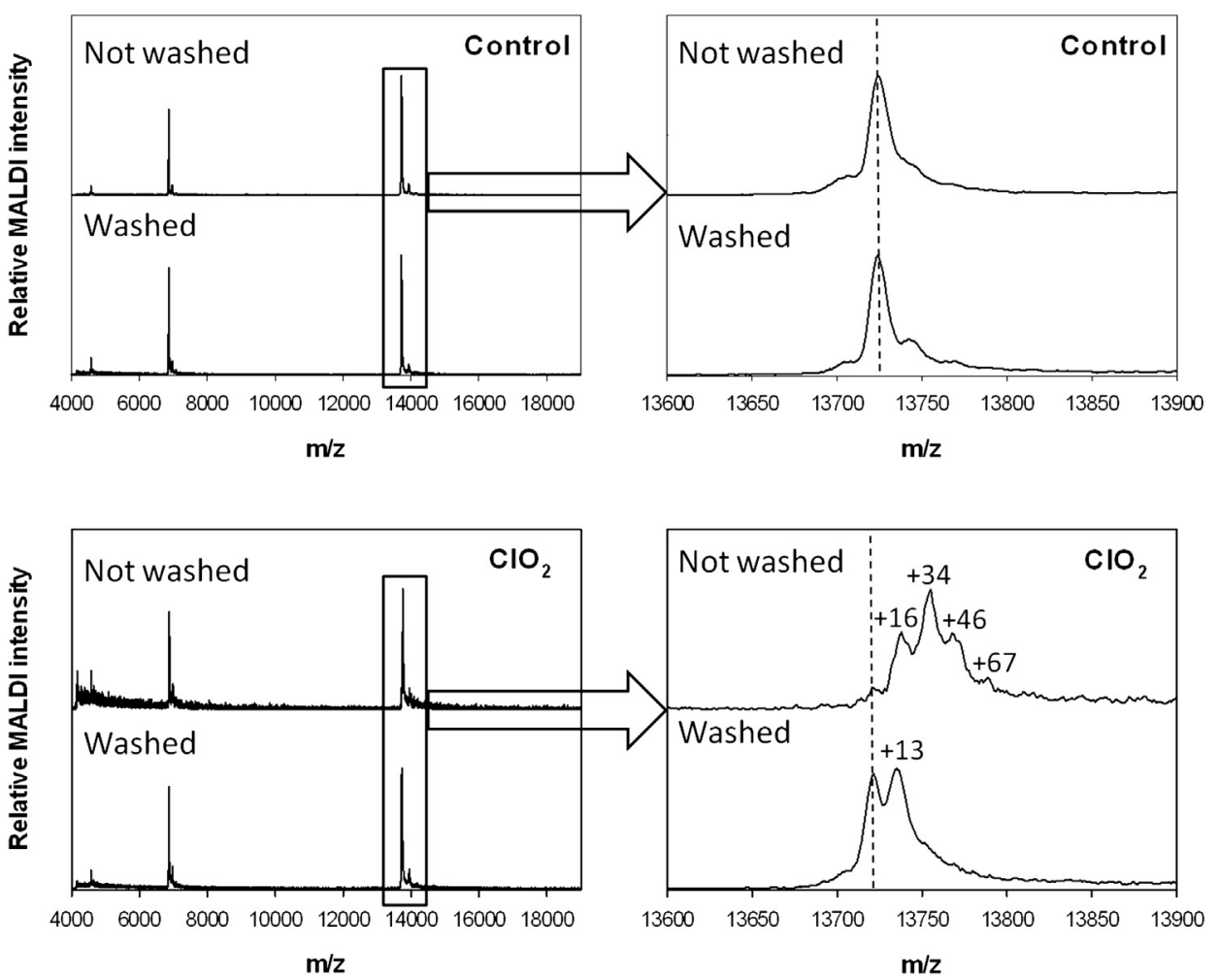

Fig. 6 - MALDI spectra of washed and unwashed MS2 samples before and after $\mathrm{ClO}_{2}$ treatment. Top panel: sample before $\mathrm{ClO}_{2}$ treatment (control); bottom panel: sample after inactivation $\left(\mathrm{ClO}_{2}\right)$. Left: overview spectra over the whole measured mass to charge $(\mathrm{m} / \mathrm{z})$ range. Right: Zoom on the $\mathbf{M}^{+1}$ capsid protein peak. The boxes and dashed lines indicate the $\mathrm{m} / \mathrm{z}$ ratio of the intact capsid protein peak. Numbers in plot indicate the mass difference between the intact capsid protein and the products formed during inactivation. 
31003A_138319) and by EPFL internal funds. We thank Urs von Gunten for helpful discussions and Satoshi Takahama for assistance with statistical analyses.

\section{Appendix A. Supplementary material}

Supplementary material associated with this article can be found, in the online version, at http://dx.doi.org/10.1016/j. watres.2013.09.023.

\section{R E F E R E N C E S}

Aieta, E.M., Berg, J.D., 1986. A review of chlorine dioxide in drinking-water treatment. J. Am. Water Works Assoc. 78, $62-72$.

Berman, D., Hoff, J.C., 1984. Inactivation of simian rotavirus sa11 by chlorine, chlorine dioxide, and monochloramine. Appl. Environ. Microbiol. 48, 317-323.

Cerf, O., 1977. Tailing of survival curves of bacterial-spores. J. Appl. Bacteriol. 42, 1-19.

Chauret, C.P., Radziminski, C.Z., Lepuil, M., Creason, R., Andrews, R.C., 2001. Chlorine dioxide inactivation of cryptosporidium parvum oocysts and bacterial spore indicators. Appl. Environ. Microbiol. 67, 2993-3001.

Chen, Y.S., Vaughn, J.M., 1990. Inactivation of human and simian rotaviruses by chlorine dioxide. Appl. Environ. Microbiol. 56, 1363-1366.

Chick, H., 1908. An investigation of the laws of disinfection. J. Hyg. 8, 92-158.

Delgado, A.V., Gonzalez-Caballero, E., Hunter, R.J., Koopal, L.K., Lyklema, J., 2005. Measurement and interpretation of electrokinetic phenomena - (iupac technical report). Pure Appl. Chem. 77, 1753-1805.

Floyd, R., Sharp, D.G., 1977. Aggregation of poliovirus and reovirus by dilution in water. Appl. Environ. Microbiol. 33, 159-167.

Floyd, R., Sharp, D.G., 1978. Viral aggregation - effects of salts on aggregation of poliovirus and reovirus at low-ph. Appl. Environ. Microbiol. 35, 1084-1094.

Gates, D., 1998. The Chlorine Dioxide Handbook. American Water Works Association.

Grabow, W.O.K., 2001. Bacteriophages: Update on application as models for viruses in water. Water Sa 27, 251-268.

Haas, C.N., Joffe, J., 1994. Disinfection under dynamic conditions - modification of hom model for decay. Environ. Sci. Technol. 28, 1367-1369.

Harakeh, M., Butler, M., 1984. Inactivation of human rotavirus, sa11 and other enteric viruses in effluent by disinfectants. J. Hyg. 93, 157-163.

Hejkal, T.W., Wellings, F.M., Lewis, A.L., Larock, P.A., 1981. Distribution of viruses associated with particles in wastewater. Appl. Environ. Microbiol. 41, 628-634.

Hiatt, C.W., 1964. Kinetics of inactivation of viruses. Bacteriol. Rev. 28, 150.

Hoigne, J., Bader, H., 1994. Kinetics of reactions of chlorine dioxide (oclo) in water. 1. Rate constants for inorganic and organiccompounds. Water Res. 28, 45-55.

Hornstra, L.M., Smeets, P., Medema, G.J., 2010. Inactivation of bacteriophage ms 2 upon exposure to very low concentrations of chlorine dioxide. Water Res. 45, 1847-1855.
Huang, J.L., Wang, L., Ren, N.Q., Liu, X.L., Sun, R.F., Yang, G.L., 1997. Disinfection effect of chlorine dioxide on viruses, algae and animal planktons in water. Water Res. 31, 455-460.

Jin, M., Shan, J., Chen, Z., Guo, X., Shen, Z., Qiu, Z., Xue, B., Wang, Y., Zhu, D., Wang, X., Li, J., 2013. Chlorine dioxide inactivation of enterovirus 71 in water and its impact on genomic targets. Environ. Sci. Technol. 47, 4590-4597.

Li, J.W., Yu, Z.B., Cai, X.P., Gao, M., Chao, F.H., 1996. Trihalomethanes formation in water treated with chlorine dioxide. Water Res. 30, 2371-2376.

Lim, M.Y., Kim, J.M., Ko, G., 2010. Disinfection kinetics of murine norovirus using chlorine and chlorine dioxide. Water Res. 44, $3243-3251$.

Mattle, M.J., Crouzy, B., Brennecke, M., Wigginton, K.R., Perona, P., Kohn, T., 2011. Impact of virus aggregation on inactivation by peracetic acid and implications for other disinfectants. Environ Sci. Technol. 45, 7710-7717.

Mattle, M.J., Kohn, T., 2012. Inactivation and tailing during uv254 disinfection of viruses: Contributions of viral aggregation, light shielding within viral aggregates, and recombination. Environ. Sci. Technol. 46, 10022-10030.

Napolitano, M.J., Green, B.J., Nicoson, J.S., Margerum, D.W., 2005. Chlorine dioxide oxidations of tyrosine, $n$-acetyltyrosine, and dopa. Chem. Res. Toxicol. 18, 501-508.

Pecson, B.M., Martin, L.V., Kohn, T., 2009. Quantitative pcr for determining the infectivity of bacteriophage ms2 upon inactivation by heat, uv-b radiation, and singlet oxygen: advantages and limitations of an enzymatic treatment to reduce false-positive results 75, 5544-5554.

Sharp, D.G., Floyd, R., Johnson, J.D., 1975. Nature of surviving plaque-forming unit of reovirus in water containing bromine. Appl. Environ. Microbiol. 29, 94-101.

Sigstam, T., Gannon, G., Cascella, M., Pecson, B.M., Wigginton, K.R., Kohn, T., 2013. Subtle differences in virus composition affect disinfection kinetics and mechanisms. Appl. Environ. Microbiol. 79, 3455-3467.

Thurston-Enriquez, J.A., Haas, C.N., Jacangelo, J., Gerba, C.P., 2003. Chlorine inactivation of adenovirus type 40 and feline calicivirus. Appl. Environ. Microbiol. 69, 3979-3985.

Thurston-Enriquez, J.A., Haas, C.N., Jacangelo, J., Gerba, C.P., 2005. Inactivation of enteric adenovirus and feline calicivirus by chlorine dioxide 71, 3100-3105.

Walter, W.G., 1961. Standard methods for the Examination of Water and Wastewater vol. 51, 940, 11th ed.

Watson, H.E., 1908. A note on the variation of the rate of disinfection with change in the concentration of the disinfectant. J. Hyg. 8, 536-542.

Wigginton, K.R., Menin, L., Montoya, J.P., Kohn, T., 2010. Oxidation of virus proteins during UV254 and singlet oxygen mediated inactivation. Environ. Sci. Technol. 44, 5437-5443.

Wigginton, K.R., Pecson, B.M., Sigstam, T., Bosshard, F., Kohn, T., 2012. Virus inactivation mechanisms: impact of disinfectants on virus function and structural integrity 46, 12069-12078.

Xie, Y.F., 2004. Disinfection Byproducts in Drinking Water; Formation, Analysis and Control. Lewis Publisher.

Xue, B., Jin, M., Yang, D., Guo, X., Chen, Z., Shen, Z., Wang, X., Qiu, Z., Wang, J., Zhang, B., Li, J., 2013. Effects of chlorine and chlorine dioxide on human rotavirus infectivity and genome stability 47, 3329-3338.

Zoni, R., Zanelli, R., Riboldi, E., Bigliardi, L., Sansebastiano, G., 2007. Investigation on virucidal activity of chlorine dioxide. Experimental data on feline calicivirus, hav and coxsackie b5 48, 91-95. 